\title{
Does openness and open access policy relate to the success of universities?
}

\author{
Pekka Olsbo \\ Jyväskylä University Library, Jyväskylä, Finland \\ E-mail: pekka.olsbo@jyu.fi
}

\begin{abstract}
This study takes a closer look at the Ranking Web of Universities and Ranking Web of Repositories rankings and tries to examine if there is a connection between these two rankings. Study is done by analyzing the success of University of Jyväskylä and the institutional repository JyX of the University in these rankings. Comparison shows that the JyX archive plays an important role in University's success especially when analyzing the presence and openness of the University. By analyzing the success of eight European countries in these rankings and cross reading these findings with the development of relative citation impact shown in a report by the Finnish Academy, some interesting common trends can be seen. The same three countries Finland, Denmark and Norway seem to be on their way up in all comparisons. Open Access activities in these countries can be seen as one explaining factor.
\end{abstract}

Keywords: Institutional repositories, Jyx, open access, open access policy, openness, Ranking Web of Repositories, Ranking Web of Universities, University of Jyväskylä, university rankings

\section{Introduction}

The cross reading and examination of the report The state of scientific research in Finland 2012 by The Finnish Academy and Ranking Web of Universities seem to show that there could be a connection between the internet visibility, ranking and the relative citation impact of universities in different countries. These relationships can be traced back to the effectiveness of the open access publishing, self-archiving and Open Access policies of the countries and the universities. This paper focuses on internet visibility of the University of Jyväskylä and eight European countries and how the openness of universities has developed during last two editions of the Ranking Web of Universities.

\section{University of Jyväskylä and the Ranking Web of Universities}

The universities of the world are ranked by several different research institutions. In this study we will take a closer look at the Ranking Web of Universities ( $R W U$ ) ranking, because it claims to be more extensive than the others and because its focus is on academic web presence of the universities. $R W U$ has analyzed over 21,000 universities and the actual ranking covers 12,000 universities. Openness of science is becoming more and more important for universities, since today science lives in the internet, as described in the methodology of the $R W U$ : "In the second decade of the 21 st century the Web is key for 
the future of all the university missions, as it is already the most important scholarly communication tool, the future channel for the off-campus distance learning, the open forum for the community engagement and the universal showcase for attracting talent, funding and resources" [1]. There are several studies which suggest that openly available science is more quickly recognized and the results are picked up and discussed by peers to a larger extent [2].

Ranking Web of Universities is based on composite indicator, which is built on four indicators: presence (weight $16.7 \%$ ), impact (weight 50\%), openness (weight 16.7\%) and excellence (weight $16.7 \%$ ) (in January 2013 edition). Presence indicator is defined as the total number of webpages hosted in the main web domain of the university as indexed by the Google. The impact indicator is evaluated through a "virtual referendum", counting all the external inlinks that the University web domain receives from third parties. In the openness indicator the global effort to set up institutional research repositories is explicitly recognized and it takes into account the number of rich files published in dedicated websites according to the Google Scholar. The excellence indicator analyzes academic papers published in high impact international journals. The indicator is restricted to only those excellent publications being part of the $10 \%$ most cited papers in their respective scientific fields. ${ }^{1}$

The University of Jyväskylä is ranked in the January 2013 edition of $R W U$ (January 2013) by different indicators as follows:

presence rank 107 (July 2012 edition: 117),

impact rank 609 (411),

openness rank 307 (562),

excellence rank 550 (549),

the total rank of Jyväskylä University is 357 (299).

As we can see, the University of Jyväskylä is ranked highest in presence rank. Since the presence indicator is analyzing the visibility of pages and files in university's domain in Google index, the University of Jyväskylä must have done something right in their domain policy. Strict one domain name policy fits very well into $R W U$ methodology.

Spanish research institution Consejo Superior de Investigaciones Científicas (CSIC) is responsible of creating the Ranking Web of Universities. They also rank repositories. In latest edition (January 2013) of Ranking Web of Repositories (RWR) over 1600 repositories all over the world are ranked.

By investigating the $R W U$ and the $R W R$ we can try to find out what kind of connections there are between these rankings. The number one ranked university in $R W U$ is Harvard. Harvard also hosts the number one institutional repository Smithsonian/NASA Astrophysics Data System together with Smithsonian Astrophysical Observatory. From other top 5 universities also MIT and University of Michigan have highly respected repositories. Brazilian university Universidade de São Paulo USP is the only university besides Oxford and Cambridge outside the United States among the 20 best universities with its rank number 19. Also the repository of the São Paulo University is highly respected in the RWR. The Universidade de São Paulo Biblioteca Digital de Teses e Dissertações is ranked at place 8.

But what kind of role does the University's institutional repository JyX (https://jyx.jyu.fi) play in Jyväskylä University's success? Site restricted search in Google shows that over 13\% of all search results which indicate to the site jyu.fi have their origin in JyX archive. And if we repeat the same search in Google Scholar, the effect of JyX archive is even more significant: over $87 \%$ of all search results come from JyX archive. So JyX archive seems to have an important role in University's presence rank. Also the

\footnotetext{
${ }^{1}$ More detailed analysis of indicators at http://www.webometrics.info/en/Methodology.
} 
rank in openness seems to develop hand in hand with the repository. Although the number of evaluated universities has risen up, the Jyväskylä University rank in openness has also risen from 562 to 307 . At the same time the rank of JyX archive has developed from 87 to 80 .

\section{Openness and relative citation impact}

The Finnish Academy published a report The state of scientific research in Finland 2012 in October 2012. In this report the Academy is analyzing the relative citation impact of Finnish research articles: "Publication numbers in Finnish science and research and citations to Finnish research publications are at a good level. Indices for the countries included in the comparison have remained more or less unchanged: changes at country level happen very slowly. Nonetheless, it is interesting to consider why Switzerland, for instance, continues to have such strong success: is there something about Swiss science and research funding or about university practices in Switzerland that could be imported and applied to Finland?" [4].

The development of relative citation impact in 2003-2010 in eight European countries is shown in the Fig. 1.

Figure 1 shows the good values of Switzerland, Netherlands and Denmark. What do they do differently from Finland in those countries? There are certainly many effecting factors but if we analyze the statistics in $R W U$ and $R W R$ we might find connections between the success of universities, ranking in openness and repositories in Switzerland, Netherlands and Denmark. The rankings of best universities and repositories and the development of openness in eight European countries are described in the Table 1.

In the table we can see that at least in Netherlands and Sweden there is a deep connection between the ranking of universities, repositories and the openness of the universities. But the most interesting developments can be seen, if we look at the trends described in Fig. 1 and Table 1. If we compare the top 5 universities of these countries we can see, that Finland, Denmark and Norway have improved their placing in openness substantially compared to Switzerland and even the whole $R W U$. These same countries seem to be in their way up also if we look at the development of relative citation impact in

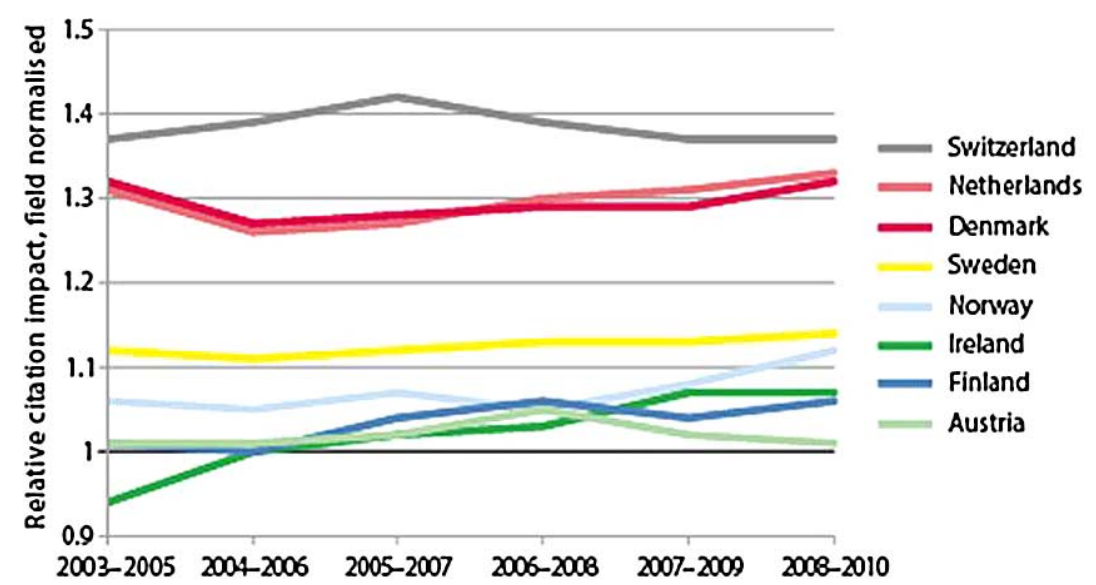

Fig. 1. Development of relative citation impact in 2003-2010. World average level is 1. Source: [4, p. 45]. (Colors are visible in the online version of the article; http://dx.doi.org/10.3233/ISU-130707.) 
Table 1

Universities and repositories in 8 European countries in Ranking Web of Universities and Ranking Web of Repositories in July 2012 and January 2013

\begin{tabular}{|c|c|c|c|c|c|c|c|c|c|}
\hline & \multicolumn{2}{|c|}{$\begin{array}{c}\text { Universities among } \\
\text { the best } 300\end{array}$} & \multirow{2}{*}{$\begin{array}{c}\begin{array}{c}\text { Repositories among } \\
\text { the best } 100\end{array} \\
1 / 2013\end{array}$} & \multicolumn{2}{|c|}{$\begin{array}{l}\text { Universities among the } \\
\text { best } 300 \text { in openness }\end{array}$} & \multicolumn{2}{|c|}{$\begin{array}{l}\text { Mean value* of top } 5 \text { universities } \\
\text { in openness rank }\end{array}$} & \multicolumn{2}{|c|}{$\begin{array}{l}\text { Median value of top } 5 \text { universities } \\
\text { in openness rank }\end{array}$} \\
\hline & $7 / 2012$ & $1 / 2013$ & & 7/2012 & $1 / 2013$ & $7 / 2012$ & $1 / 2013$ & $7 / 2012$ & $1 / 2013$ \\
\hline Austria & 3 & 3 & 1 & 2 & 2 & 283 & 349 & 383 & 417 \\
\hline Denmark & 4 & 3 & 2 & 2 & 4 & 244 & 215 & 308 & 175 \\
\hline Finland & 2 & 1 & 2 & 2 & 3 & 323 & 188 & 346 & 168 \\
\hline Ireland ${ }^{* *}$ & 1 & 1 & 0 & 0 & 0 & 763 & 660 & 846 & 727 \\
\hline Netherlands & 11 & 10 & 7 & 11 & 10 & 26 & 48 & 19 & 57 \\
\hline Norway $^{* *}$ & 3 & 3 & 1 & 2 & 2 & 507 & 240 & 357 & 180 \\
\hline Sweden & 8 & 7 & 2 & 7 & 7 & 116 & 102 & 133 & 98 \\
\hline Switzerland & 5 & 5 & 3 & 5 & 3 & 146 & 225 & 125 & 273 \\
\hline
\end{tabular}

* Mean value is calculated by dividing the sum of rankings in openness by 5 . Smaller number means better ranking.

** Only top 4 universities calculated. 
recent years. The positions of Switzerland and Austria have weakened in both openness and relative citation impact. Actually these trends seem to go hand in hand in all eight countries.

One explaining factor could be the Open Access policy of these countries and universities. In Finland the dramatic improvement in openness ranking of the University of Helsinki (71 to 5) is at least partly due to their mandate for self-archiving and their developmental work in repositories. Universities in Jyväskylä and Tampere have strong recommendations for self-archiving and are doing active work in promoting open access. The Danish Open Access Committee published its recommendations for national Open Access policy in 2011 [3]. Now the number of top 300 universities in openness has risen from 2 to 4 in six months. Is it due to proper Open Access policy of the country, coincidence or unreliability of the methodology of Ranking Web of Universities is hard to say yet.

\section{References}

[1] http://www.webometrics.info/en/Methodology; cited 10.10.2012.

[2] G. Eysenbach, Citation advantage of open access articles, PLoS Biol. 4(5) (2006), e157.

[3] Recommendations for Implementation of Open Access in Denmark 2011, 16, Final report from the Open Access Committee, available at: www.fi.dk.

[4] L. Treuthardt and A. Nuutinen (eds), The state of scientific research in Finland 2012, Publications of the Academy of Finland 7/12, 2012. 